\title{
Characterisation and cellular localisation of the immunodominant 47-Kda antigen of Candida albicans
}

\author{
RUTH MATTHEWS, C. WELLS* and J. P. BURNIE
}

Departments of Medical Microbiology and "Histopathology, St Bartholomew's Hospital, West Smithfield, London EC1A $7 B E$

\begin{abstract}
Summary. The 47-Kda component of Candida albicans is an immunodominant antigen in the serology of systemic candidosis. Immuno-electronmicroscopy with an affinitypurified antibody to the $47-\mathrm{Kda}$ antigen showed that it was present in the cytoplasm and cell wall of both yeast and mycelial cells. It was found in discrete areas on the inner and outer borders of the cell wall and was mainly located within the wall rather than exposed on the outer surface. Sometimes it appeared to be in channels across the cell wall. In the cytoplasm, it was usually near the cytoplasmic membrane and occasionally appeared in vesicular areas. It was not detected in the nucleus or mitochondria. The 47-Kda antigen did not bind to Concanavalin A, and antigenicity was lost after protease digestion. Peptide mapping suggested that the antigen was highly conserved between different strains of C.albicans.
\end{abstract}

\section{Introduction}

The incidence of systemic candidosis is increasing and the mortality rate remains high at over $70 \%$ (Meunier-Carpentier et al., 1981). The diagnosis is difficult to make clinically and blood cultures are negative in up to $56 \%$ of necropsy-proven cases (de Repentigny and Reiss, 1984). There is, therefore, much interest in developing a reliable serodiagnostic test. Several reverse passive latex agglutination tests (RPLA) have recently been developed, one of which is available commercially (Ramco Candtec). Some of these tests have used latex particles sensitised with rabbit antiserum raised against heat-killed Candida albicans blastospores but appear to detect a heat-labile antigen circulating in the serum (Gentry et al., 1983; Bailey et al., 1985). This antigen has been regarded as "cytoplasmic", as distinct from the better characterised heat-stable cell-wall mannoprotein detected by other latex tests (Kahn and Jones, 1986).

In an attempt to identify immunodominant antigens we assayed serial sera from patients with systemic candidosis against immunoblots of $C$. albicans (Matthews et al., 1984; Matthews et al., 1987). We found that $92 \%$ of patients with candidal antibodies produced a response to an antigen of $47 \mathrm{Kda}$. Ability to produce and maintain a good antibody response to this antigen was associated with recovery from candidosis whereas fatal cases

Received 24 Dec. 1987; revised version accepted 12 April 1988. produced little or no antibody, or initially had antibody which subsequently fell in titre as their condition deteriorated. We next isolated the 47$\mathrm{Kda}$ antigen from the sera of patients with systemic C. albicans infections and showed that the amount of antigen present correlated with the antigen titre obtained with our RPLA test (Burnie et al., 1985a), in which particles are sensitised with rabbit antiserum against a pressate of C. albicans (Burnie, 1985). This would be consistent with the $47 \mathrm{Kda}$ antigen being a major immunodominant component of the many antigens measured by such RPLA.

Greenfield and Jones (1981) described a major cytoplasmic antigen of $54.3 \mathrm{Kda}$ (range 48.9-59.7 $\mathrm{Kda}$ ) which was released from $C$. albicans during the course of invasive infections and elicited a specific antibody response in man and in experimental animals. Jones (1980) suggested, on the basis of the high titres of antibodies to the fraction containing this antigen in hyperimmunised mice, that antibody to this antigen was responsible for resistance to $C$. albicans infections. An immunodominant antigen of similar molecular weight (44$52 \mathrm{Kda})$ has been identified by Strockbine et al. $(1984 a)$ in an extract of $C$. albicans, grown in the mycelial phase and passed through a Concanavalin A sepharose affinity column to remove mannan. This antigen was recognised by antibodies in the sera of seven out of ten patients with disseminated candidosis. Au-Young et al. (1985) examined sera from 15 patients with systemic candidosis by 
immunoblot analysis against a French-press extract of $C$. albicans and tested for anti-mannan antibody by an enzyme-linked immunosorbent assay (ELISA). They again described an immunodominant cytoplasmic antigen of similar molecular weight $(45 \mathrm{Kda})$ and found that measurement of antibody to this antigen was more specific to systemic candidosis than anti-mannan antibody. Neale et al. (1987) identified the 47-Kda antigen in circulating immune complexes in the serum of a patient with C. albicans osteomyelitis.

It seems likely that these immunodominant cytoplasmic antigens are equivalent or closely related, the difference in molecular weight being due to the different methods of antigen preparation. Very little is known of the nature of this antigen and its role, if any, in the pathogenesis of candidal infections. In this paper we report the location of the 47-Kda antigen in C. albicans yeast and mycelial cells. We have also determined the extent to which it is conserved between different strains of $C$. albicans by peptide mapping.

\section{Materials and methods}

\section{Affinity-purified antibody}

A pressate of $C$. albicans NCPF strain 3153, serotype A was prepared in an Xpress (LKB, Bromma, Sweden) at a pressure of $200 \mathrm{mPa}$ at $-20^{\circ} \mathrm{C} ; 25 \mathrm{mg}$ of this pressate was mixed with $0.2 \mathrm{ml}$ of Freund's complete adjuvant and injected subcutaneously into three New Zealand White rabbits. A further injection was given 14 days later and serum was collected after 28 days. This serum contained high levels of candidal antibodies as determined by assay against an immunoblot of the $C$. albicans pressate, as previously described (Burnie et al., 1985b). It was fractionated to produce monospecific antibody to the 47-Kda antigen by a modification of the method of Olmsted (1981). The candidal pressate was boiled for $5 \mathrm{~min}$ with cracking buffer sodium dodecyl sulphate $2.6 \%, 2$-mercaptoethanol $1 \cdot 3 \%$, glycerol $6 \%$, bromophenol blue $0.2 \%, 0.05 \mathrm{M}$ Tris hydrochloride, $\mathrm{pH} 6.8$ ). It was then loaded on to a $10 \%$ polyacrylamide gel. Electrophoresis and immunoblotting on to nitrocellulose membrane were performed as previously described (Matthews et al., 1984). The horizontal band containing the $47-\mathrm{Kda}$ antigen was excised. Free protein binding sites were blocked with non-fat dry milk $5 \% \mathrm{w} / \mathrm{v}$ in phosphatebuffered saline (PBS) pH 7.4. The strip was washed in PBS and then incubated for $2 \mathrm{~h}$ with the rabbit antiserum against $C$. albicans pressate. Then the strip was washed and the bound antibody eluted with glycine buffer $(0.2 \mathrm{M}$ glycine, 1 mM EGTA, pH 2.7). This was neutralised by adding an equal volume of $10 \mathrm{~mm}$ Tris base. The specificity of the affinity-purified anti-47-Kda antigen probe was confirmed by immunoblotting against the pressate of $C$. albicans. The same procedure was applied to a rabbit hyperimmune antiserum to Aspergillus to obtain affinity-purified antibody against a $40-\mathrm{Kda}$ antigen of $\boldsymbol{A}$. fumigatus. Briefly, a rabbit was immunised by repeated subcutaneous injections of a pressate of $A$. fumigatus ( $25 \mathrm{mg}$ ) mixed with $0 \cdot 2 \mathrm{ml}$ of Freund's complete adjuvant and successful immunisation was determined by assay against an immunoblot of $A$. fumigatus. Electrophoresis and immunoblotting of $A$. fumigatus were performed as previously described (Matthews et al., 1985). The horizontal band containing the 40-Kda antigen was excised and monospecific antibody prepared against it as described above.

\section{Growth conditions for C. albicans}

To obtain the yeast phase, C. albicans NCPF 3153 was inoculated into $10 \mathrm{ml}$ of glucose broth $2 \%$ and grown overnight at $37^{\circ} \mathrm{C}$ with aeration. The mycelial phase was grown in $10 \mathrm{ml}$ of Eagle's minimal essential medium supplemented with $1 \mathrm{ml}$ fetal calf serum. Under these conditions about $70 \%$ of cells were in the mycelial phase.

\section{Immuno-electronmicroscopy}

Cell suspensions $\left(c .2 \times 10^{6}\right.$ cells $\left./ \mathrm{ml}\right)$ were washed three times with PBS, pH 7.4, and then fixed in suspension in PLP fixative (McLean and Nakane, 1974) containing paraformaldehyde $4 \%$ for $20 \mathrm{~min}$ at room temperature. After washing three times with PBS the cells were quenched in $0.5 \mathrm{M}$ ammonium chloride for $4 \mathrm{~h}$, then washed in PBS and pelleted into $2 \%$ low gelling temperature agar. They were dehydrated to $70 \%$ ethanol and then embedded in $\mathrm{L} R$ White resin and polymerised at $50^{\circ} \mathrm{C}$ for $24 \mathrm{~h}$ (Newman et al., 1982). Sections $70 \mathrm{~mm}$ thick were cut and mounted on formvar coated copper grids. Immuno-labelling was performed with the monospecific antibody to the 47-Kda antigen and binding sites were visualised with 5-nm gold particle goat anti-rabbit $\operatorname{IgG}$ probe. Sections were then stained with saturated aqueous uranyl acetate acid and Reynold's lead citrate and examined in a JEOL 100SX transmission electronmicroscope. Control sections were incubated with preimmune rabbit serum or affinity purified antibody against the $40-\mathrm{Kda}$ antigen of $A$. fumigatus. Sections were also treated with the 5-nm gold probe without prior incubation with the affinity purified candidal antibody.

\section{Protease digestion}

The pressate of $C$. albicans NCPF 3153, protein concentration $1 \mathrm{mg} / \mathrm{ml}$, was incubated at $37^{\circ} \mathrm{C}$ overnight with (i) pronase $(0.1 \mathrm{mg} / \mathrm{ml}$; Sigma) in $10 \mathrm{mM}$ Tris chloride pH 7.5-1 mM EDTA (TE); (ii) trypsin $(0.1 \mathrm{mg} /$ $\mathrm{ml}$; Sigma), in PBS, pH 7.5; (iii) TE without enzyme; (iv) PBS without enzyme. Each preparation was then separated on a SDS polyacrylamide gel, immunoblotted 
and probed with the affinity purified antibody against the 47-Kda antigen.

\section{Sodium periodate}

The pressate of $C$. albicans NCPF 3153, protein concentration $1 \mathrm{mg} / \mathrm{ml}$ was incubated in the dark at $20^{\circ} \mathrm{C}$ overnight with (i) $0 \cdot 1 \mathrm{M}$ sodium periodate in $0 \cdot 1 \mathrm{M}$ sodium acetate buffer, pH 5 (ii), $0 \cdot 1 \mathrm{~m}$ sodium acetate buffer, $\mathrm{pH}$ 5 , without sodium periodate. Excess periodate was neutralised by adding an equal molarity of ethylene glycol before gel electrophoresis, immunoblotting and probing with the affinity-purified antibody against the $47-\mathrm{Kda}$ antigen.

\section{Concanavalin A}

After electrophoresis of the pressate and transfer on to nitrocellulose membrane, it was blocked with bovine serum albumin $3 \%$ in Tris-buffered saline, $\mathrm{pH} 7 \cdot 5$, at $4{ }^{\circ} \mathrm{C}$ overnight. It was then washed in Tris-buffered saline and incubated for $2 \mathrm{~h}$ at room temperature with $100 \mu \mathrm{l}$ of Concanavalin $\mathrm{A} /$ horseradish peroxidase in Tris-buffered saline. After washing five times in Tris-buffered saline this was stained with $30 \mu \mathrm{l}$ of $\mathrm{H}_{2} \mathrm{O}_{2}$ and $35 \mathrm{mg}$ of 4chloronaphthol in methanol: Tris-buffered saline $(1: 6)$.

\section{Peptide mapping}

Pressates were prepared from the yeast and mycelial phases of C. albicans NCPF 3153 and from the strain of C. albicans responsible for the outbreak of systemic candidosis on the intensive care unit at The London Hospital (Burnie et al., 1985c). Pressates were prepared from the yeast phase of two other strains of $C$. albicans, chosen because they were among the commonest types identified by immunoblot fingerprinting (Lee et al., 1986). These four strains represented $71 \%$ (158 of 190 isolates) of isolates typed by immunoblot fingerprinting.

Each pressate was run on an SDS $10 \%$ polyacrylamide gel and then the $47-\mathrm{Kda}$ band was visualised by staining with a silver stain kit (Amersham International, Amersham, UK). The bands were cut from the gel, equilibrated with stacking buffer $(0 \cdot 125 \mathrm{M}$ Tris $\mathrm{HCl} \mathrm{pH} 6 \cdot 8$, SDS $0 \cdot 1 \%$ and $1 \mathrm{~mm}$ EDTA) and set into the sample wells of a second SDS gel as described by Cheung et al. (1987). The second gel consisted of a $15 \%$ acrylamide resolving gel and a stacking gel of $6 \%$ acrylamide with $1 \mathrm{~mm}$ EDTA. Each gel slice was overlaid with $5 \mu \mathrm{g}$ of chymotrypsin (type 1S; Sigma) in sample buffer (0.125 M Tris, pH 6.8, SDS $0 \cdot 1 \%$, glycerol $10 \%$, bromophenol blue $0.002 \%$ ). Electrophoresis was performed in the normal manner except that the current was turned off for $30 \mathrm{~min}$ when the bromophenol blue dye neared the bottom of the stacking gel. After blotting onto nitrocellulose membrane, the peptide digests were probed with hyperimmune rabbit antiserum to $C$. albicans diluted 1 in 25 in $3 \%$ bovine serum albumin buffered saline as previously described (Matthews et al., 1987).

\section{Results}

\section{Specificity of antibody}

The monospecificity of the affinity-purified antibody against the 47-Kda antigen of $C$. albicans was confirmed by immunoblotting. At a dilution of 1 in 400 in bovine serum albumin $3 \%$ in buffered saline, the affinity-purified antibody gave a single prominent band at 47-Kda and very little reactivity with any of the other candidal antigens (fig. 1).

\section{Immuno-electronmicroscopy}

The antibody probe against the $47-\mathrm{Kda}$ antigen of $C$. albicans produced the pattern of labelling illustrated in figs. 2-5. Reactivity was specific to this affinity-purified antibody and not present with any of the controls. The $47-\mathrm{Kda}$ antigen was detected in both the yeast and the mycelial phase of $C$. albicans. It was located in the cytoplasm and the cell wall but not in the nucleus (fig. 2). In the cytoplasm it was usually located near the cytoplasmic membrane and adjacent to areas on the inner and outer borders of the cell wall showing strong concentrations of the antigen. Occasionally it localised in vesicular areas in the cytoplasm which appeared to be associated with endoplasmic reticulum (fig. 3). It was not uniformly distributed in the cell wall but located in discrete areas on both

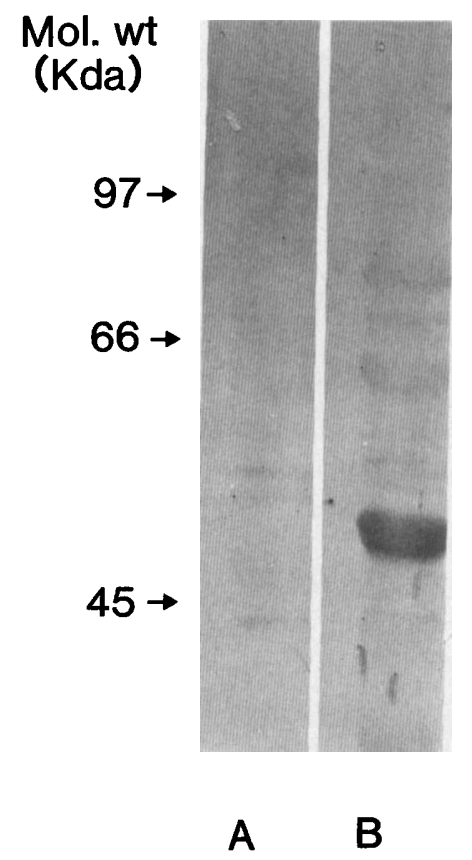

Fig. 1. Immunoblot of $C$. albicans probed with (A) pre-immune rabbit serum,(B)affinity-purified antibody to the $47-\mathrm{Kda}$ antigen. 


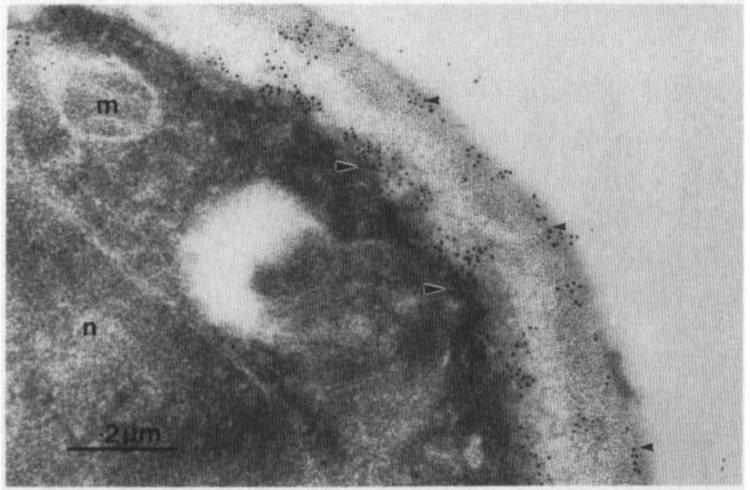

Fig. 2. C. albicans showing labelling of $47-\mathrm{Kda}$ antigen in the cytoplasm (large arrows) and cell wall (small arrows). The nucleus $(\mathrm{n})$ and mitochondria $(\mathrm{m})$ however are free of label; $\times 110000$.

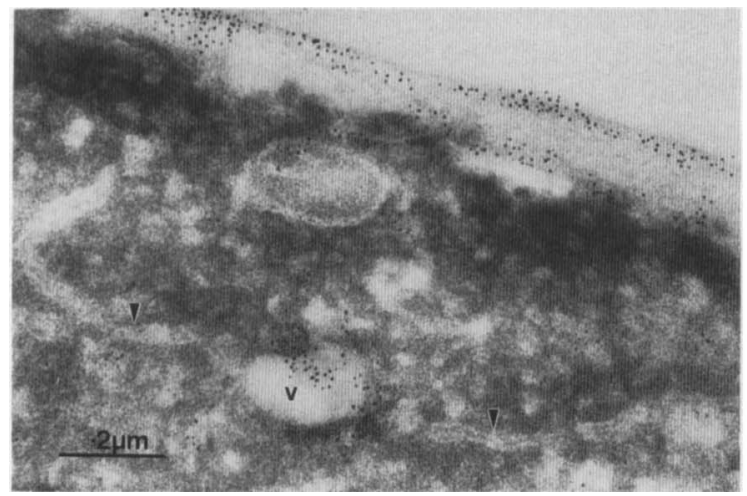

Fig. 3. Vesicle (v) within the cytoplasm showing labelling of the 47-Kda antigen. Structures resembling endoplasmic reticulum can also be seen (arrows); $\times 110000$.

sides of the wall. In places, the antigen appeared to be in a channel through the cell wall (fig. 4). The antigen was found on developing septa of dividing cells (fig. 5).

\section{Protease digestion}

Incubation of the pressate of $C$. albicans with pronase or trypsin, followed by electrophoresis and immunoblotting, led to complete loss of reactivity with antibody to the $47-\mathrm{Kda}$ antigen. There was no loss of reactivity following incubation with buffer alone.

\section{Sodium periodate and Concanavalin A}

Antigenicity was lost after incubation with sodium acetate, $\mathrm{pH} \mathrm{5}$, alone; therefore, it is not possible to comment on the effect of periodate

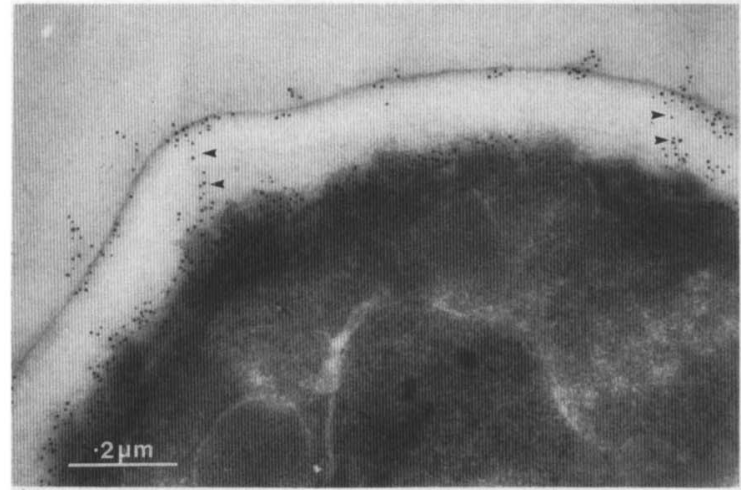

Fig. 4. Labelling of $47-\mathrm{Kda}$ antigen on the outer aspect of the cell wall showing antigen distributed at intervals mainly within the cell wall. The antigen also appears in channels through the cell wall (arrows); $\times 110000$.

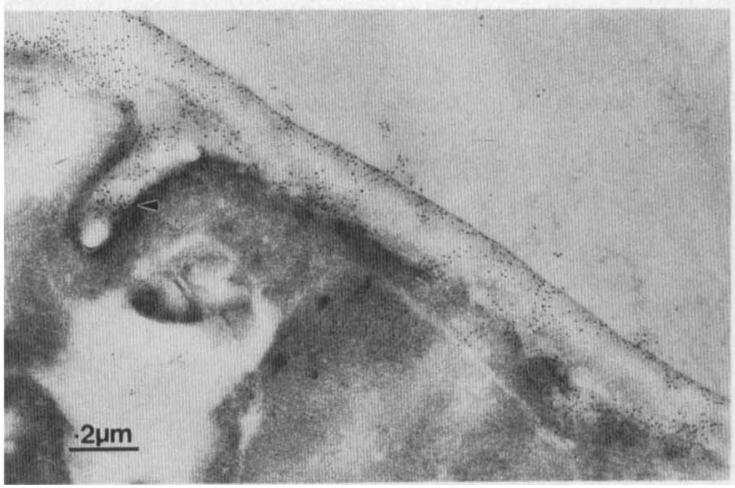

Fig. 5. Mycelium showing 47-Kda antigen along the outer and inner borders of the cell wall and also on a developing septum (arrow); $\times 70000$.

oxidation. The $47-\mathrm{Kda}$ antigen did not bind to Concanavalin A. Multiple bands of higher molecular weight did bind to Concanavalin $\mathrm{A}$.

\section{Peptide mapping}

The chymotrypsin digests of the $47-\mathrm{Kda}$ bands isolated from four different strains of $C$. albicans were indistinguishable. Apart from some undigested 47-Kda antigen, two further bands of lower molecular weight are prominent (fig. 6). The same digest pattern was obtained whether the $47-\mathrm{Kda}$ antigen was prepared from the yeast or mycelial phase.

\section{Discussion}

Each group working on the antigen has described it as a major immunodominant component of the 


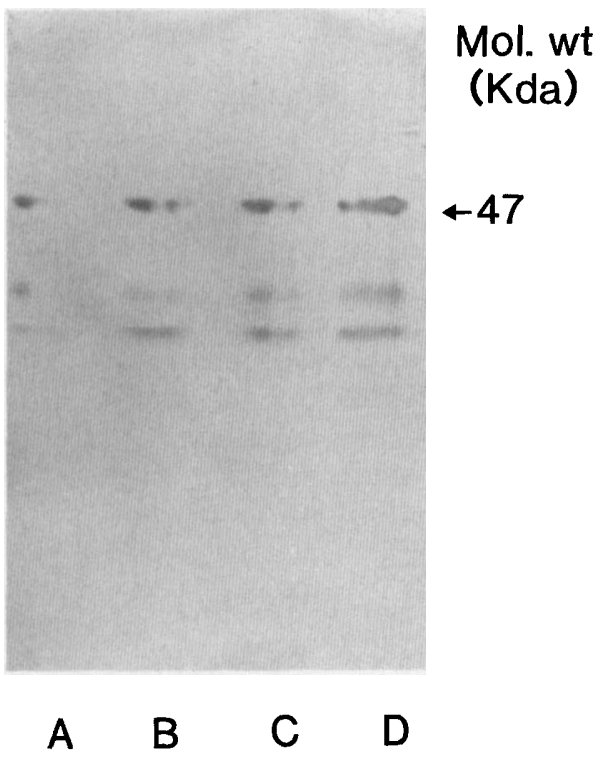

Fig. 6. Peptide mapping of the 47-Kda antigen prepared from the yeast (A) and mycelial (B) phases of C. albicans NCPF 3153 serotype $A$, and from the yeast phases of an outbreak strain of C. albicans (C) and C. albicans NCPF 3156, serotype B (D).

cytoplasm and identified it in soluble extracts prepared after mechanical disruption of C. albicans in the yeast phase (Greenfield and Jones, 1981; Matthews et al., 1984; Au-Young et al., 1985) or the mycelial phase (Strockbine et al., 1984a). It has also been isolated from the serum of systemically infected patients (Matthews et al., 1987; Neale et al., 1987). Recently we have used an antibody probe against the $47-\mathrm{Kda}$ antigen to develop a serodiagnostic test for systemic candidosis (Matthews and Burnie, in press).

Immuno-electronmicroscopy with a monospecific affinity-purified antibody to the $47-\mathrm{Kda}$ antigen confirmed the presence of the antigen in both yeast and mycelial cells. It was present in the cytoplasm and concentrated in discrete areas on both the inner and outer borders of the cell wall. Sometimes it appeared to be in channels across the cell wall. The antigen near the outer surface of the cell wall seemed to be mainly located within the cell wall rather than exposed on the cell-wall outer surface (figs. 2-5). There is evidence to suggest that the antigen is not easily accessible to antibody. Jones (1980) found that when antiserum raised against cytoplasmic extract was cross-absorbed with whole yeast or mycelial cells there was little or no reduction in antibody to the ammonium sulphate-soluble fraction which contained the immunodominant antigen. Perhaps the $47-\mathrm{Kda}$ antigen present on the cell wall is masked by other cell surface components so that it is not readily accessible to antibody.

Unfortunately the PLP fixative and short fixation time, chosen because it had less effect on the antigenicity of the 47-Kda antigen than glutaraldehyde, did not preserve all organelles sufficiently well for definite identification. Nevertheless, in some sites in the cytoplasm, the $47-\mathrm{Kda}$ antigen appeared to be associated with membranous vesicles which may have been golgi apparatus (fig. 3). Secreted proteins are synthesised on ribosomes in the cytoplasm, become bound to the endoplasmic reticulum and are then transported via vesicles through the golgi stack before appearing on the cell surface. If the $47-\mathrm{Kda}$ antigen is such a protein, determining its amino-acid sequence may identify a sorting signal, a sequence of amino acids which specifies the endoplasmic reticulum as its first destination.

Mannan is a major component of the candidal cell wall, but the 47-Kda antigen is not a mannoprotein because it does not bind to Concanavalin $\mathrm{A}$. The same observation was made for the immunodominant antigens described by Strockbine et al. (1984a) and Au-Young et al. (1985). Each group of investigators has independently concluded that the immunodominant antigen is a protein on the basis of limited proteolysis (Strockbine et al., 1984b), its ability to stain with Coomassie blue and failure to stain with periodic acid/Schiff reagent (Au-Young et al., 1985), and amino acid analysis (Greenfield and Jones, 1981; Burnie et al., 1985a). Greenfield and Jones (1981) found that the antigen was $5 \%$ carbohydrate. Therefore, the possibility exists that the antigenic determinants are carbohydrates attached to a protein. Jones (1980) found that antigenicity was lost following treatment with either periodate (which oxidises carbohydrates) or pronase. He suggested that the antigenic determinants contained carbohydrates and their expression required the native tertiary structure of the protein portion of the antigen. However, the immunodominant antigens described by Au-Young et al. (1985), Strockbine et al. (1984a) and by ourselves, retained their antigenicity after denaturing by boiling in 2mercaptoethanol and SDS before electrophoresis and even after limited proteolysis. This is consistent with the antigenic determinants being defined by the primary structure of the protein but does not exclude the possibility of carbohydrate determinants. Like Jones (1980), we found that proteinases caused loss of antigenicity but we were unable to determine the effect of periodate because the

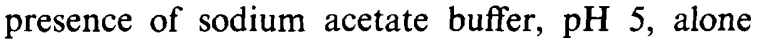
removed antigenicity. 
If probes to the $47-\mathrm{Kda}$ antigen are to be used to develop tests for the serological diagnosis of systemic candidosis it is important to determine whether this antigen is conserved between different strains of $C$. albicans. Limited proteolysis with chymotrypsin was employed to determine the relatedness of the $47-\mathrm{Kda}$ antigen isolated from four different strains and from the yeast and mycelial phases of two strains. The results indicate that the proteins had a similar primary sequence since they gave a series of polypeptides with the same moleculaı weights when digested with chymotrypsin. Strockbine et al. (1984b) applied limited proteolysis to three candidal proteins immunoprecipitated by monoclonal antibodies to the immunodominant antigen and demonstrated a significant

\section{REFERENCES}

Au-Young J K, Troy F A, Goldstein E 1985 Serologic analysis of antigen-specific reactivity in patients with systemic candidiasis. Diagnostic Microbiology and Infectious Disease 3: 419-432.

Bailey J W, Sada E, Brass C, Bennett J E 1985 Diagnosis of systemic candidiasis by latex agglutination for serum antigen. Journal of Clinical Microbiology 21 : 749-752.

Burnie J P 1985 A reverse passive latex agglutination test for the diagnosis of systemic candidosis. Journal of Immunological Methods 82: 267-280.

Burnie J P, Matthews R C, Featherbe D, Tabaqchali S $1985 a$ $47 \mathrm{kD}$ antigen of Candida albicans. Lancet 1 : 1155 (letter).

Burnie J P, Matthews R C, Fox A, Tabaqchali S $1985 b$ Use of immunoblotting to identify antigenic differences between the yeast and mycelial phases of Candida albicans. Journal of Clinical Pathology 38: 701-706.

Burnie J P, Odds F C, Lee W E, Webster C, Williams J D 1985c Outbreak of systemic Candida albicans in intensive care unit caused by cross-infection. British Medical Journal 290: 746-748.

Cheung A L, Bayer A S, Peters J, Ward J I 1987 Analysis by gel electrophoresis, western blot and peptide mapping of protein heterogeneity in Staphylococcus aureus strains. Infection and Immunity 55: 843-847.

de Repentigny L, Reiss E 1984 Current trends in immunodiagnosis of candidiasis and aspergillosis. Reviews of Infectious Diseases 6: 301-312.

Gentry L O, Wilkinson I D, Lea A S, Price M F 1983 Latex agglutination test for detection of candida antigen in patients with disseminated disease. European Journal of Clinical Microbiology 2: 122-128.

Greenfield R A, Jones J M 1981 Purification and characterization of a major cytoplasmic antigen of Candida albicans. Infection and Immunity 34 : 469-477.

Jones J M 1980 Quantitation of antibody against cell wall mannan and a major cytoplasmic antigen of Candida in rabbits, mice and humans. Infection and Immunity 30: 7879.

Kahn F W, Jones J M 1986 Latex agglutination tests for degree of relatedness in the primary structure of this antigen with two other proteins.

In conclusion, immunogold labelling suggests that the $47-\mathrm{Kda}$ antigen of C. albicans is produced in the cytoplasm and is present within the cell wall of both yeast and mycelial cells. Its preponderance and conservation in structure between different strains explains its predominance in the sera of patients with invasive candidosis (Matthews et al., 1987; Neale et al., 1987) and suggests that assays detecting the $47-\mathrm{Kda}$ antigen would form more sensitive and specific serodiagnostic tests. Its role in the disease process remains unclear.

RCM is a Wellcome Senior Research Fellow.

detection of candida antigen in sera of patient with invasive candidiasis. Journal of Infectious Diseases 153: 579-585.

Lee W, Burnie J P, Matthews R C 1986 Fingerprinting Candida albicans. Journal of Immunological Methods 93: 177-182.

Matthews R C, Burnie J P, Tabaqchali S 1984 Immunoblot analysis of the serological response in systemic candidosis. Lancet 2 : 1415-1418.

Matthews R C, Burnie J P, Fox A, Tabaqchali S 1985 Immunoblot analysis of the serological responses in invasive aspergillosis. Journal of Clinical Pathology 38: 1300-1303.

Matthews R C, Burnie J P, Tabaqchali S 1987 Isolation of immunodominant antigens from sera of patients with systemic candidiasis and characterization of serological response to Candida albicans. Journal of Clinical Microbiology 25: $230-237$.

McLean I W, Nakane P K 1974 Periodate-lysine-paraformaldehyde fixative. A new fixative for immunoelectron microscopy. Journal of Histochemistry and Cytochemistry 22 : 10771083.

Meunier-Carpentier F, Kiehn T E, Armstrong D 1981 Fungemia in the immunocompromised host. Changing patterns, antigenemia, high mortality. American Journal of Medicine 71, 363-370.

Neale T J, Muir J C, Drake B 1987 The immunochemical characterisation of circulating immune complex constituents in Candida albicans osteomyelitis by isoelectric focusing, immunoblot and immunoprint. Australian and New Zealand Journal of Medicine 17: 201-209.

Newman G R, Jasani B, Williams E D 1982 The preservation of ultrastructure and antigenicity. Journal of Microscopy 127: RP5-RP6.

Olmsted J B 1981 Affinity purification of antibodies from diazotized paper blots of heterogeneous protein samples. Journal of Biological Chemistry 256: 11955-11957.

Strockbine N A, Largen M T, Zweibel S M, Buckley H R $1984 a$ Identification and molecular weight characterization of antigens from Candida albicans that are recognized by human sera. Infection and Immunity 43: 715-721.

Strockbine N A, Largen M T, Buckley H R $1984 b$ Production and characterization of three monoclonal antibodies to Candida albicans proteins. Infection and Immunity 43: 10121018. 